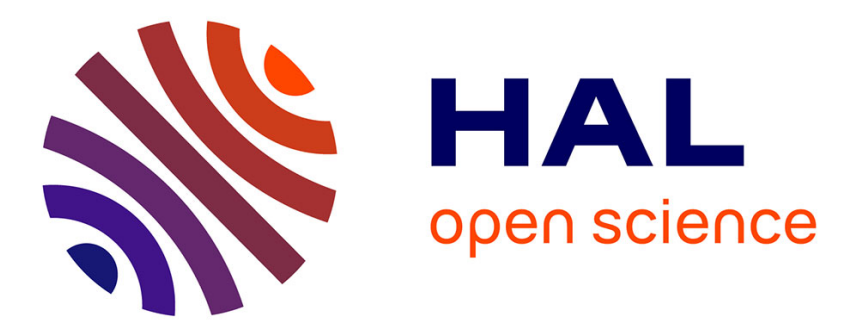

\title{
Relationships between the Antarctic Oscillation, the Madden-Julian Oscillation and ENSO, and consequences for rainfall analysis
}

Benjamin Pohl, Nicolas Fauchereau, Chris J Reason, Mathieu Rouault

\section{- To cite this version:}

Benjamin Pohl, Nicolas Fauchereau, Chris J Reason, Mathieu Rouault. Relationships between the Antarctic Oscillation, the Madden-Julian Oscillation and ENSO, and consequences for rainfall analysis. Journal of Climate, 2010, 23 (2), pp.238-254. 10.1175/2009JCLI2443.1 . hal-00411092

\author{
HAL Id: hal-00411092 \\ https://hal.science/hal-00411092
}

Submitted on 14 Jan 2022

HAL is a multi-disciplinary open access archive for the deposit and dissemination of scientific research documents, whether they are published or not. The documents may come from teaching and research institutions in France or abroad, or from public or private research centers.
L'archive ouverte pluridisciplinaire HAL, est destinée au dépôt et à la diffusion de documents scientifiques de niveau recherche, publiés ou non, émanant des établissements d'enseignement et de recherche français ou étrangers, des laboratoires publics ou privés.

\section{(ㄷ)(1) $\$$}

Distributed under a Creative Commons Attribution - NonCommerciall 4.0 International 


\title{
Relationships between the Antarctic Oscillation, the Madden-Julian Oscillation, and ENSO, and Consequences for Rainfall Analysis
}

\author{
B. POHL \\ Centre de Recherches de Climatologie, CNRS/Université de Bourgogne, Dijon, France \\ N. FAUCHEREAU \\ Department of Oceanography, Marine Research Institute, University of Cape Town, and Ocean Systems and Climate, \\ Council for Scientific and Industrial Research, Cape Town, South Africa \\ C. J. C. REASON AND M. RouAUlT \\ Department of Oceanography, Marine Research Institute, University of Cape Town, Cape Town, South Africa
}

\begin{abstract}
The Antarctic Oscillation (AAO) is the leading mode of atmospheric variability in the Southern Hemisphere mid- and high latitudes (south of $20^{\circ} \mathrm{S}$ ). In this paper, the authors examine its statistical relationships with the major tropical climate signals at the intraseasonal and interannual time scales and their consequences on its potential influence on rainfall variability at regional scales. At the intraseasonal time scale, although the AAO shows its most energetic fluctuations in the 30-60-day range, it is not unambiguously related to the global-scale Madden-Julian oscillation (MJO) activity, with in particular no coherent phase relationship with the MJO index. Moreover, in the high southern latitudes, the MJO-associated anomaly fields do not appear to project coherently on the well-known AAO patterns and are never of an annular nature. At the interannual time scale, a strong teleconnection with ENSO is found during the peak of the austral summer season, corroborating previous studies. El Niño (La Niña) tends to correspond to a negative (positive) AAO phase. The results are statistically significant only when the seasonal mean fields averaged for the November through February season are considered.

Based on these results, the authors then isolate the specific influence of the AAO on rainfall variability at both intraseasonal and interannual time scales. The example taken here is southern Africa, a region under the influence of both the MJO and ENSO, experiencing its main rainy season in austral summer and containing a relatively dense network of rain gauge measurements. At the interannual time scale, the significance of the teleconnections between southern African rainfall and the AAO reveals itself to be a statistical artifact and becomes very weak once the influence of ENSO is removed. At the intraseasonal time scale, the AAO is seen to significantly affect the rainfall amounts over much of the country, without interference with other modes of variability. Its influence in modulating the rain appears to be strongest during La Niña years.
\end{abstract}

\section{Introduction}

The Antarctic Oscillation (AAO) (Rogers and van Loon 1982; Thompson and Wallace 2000), also called the southern annular mode (SAM), is the leading mode of atmospheric low-frequency variability south of $20^{\circ} \mathrm{S}$. It basically consists of a seesaw in atmospheric pressure

Corresponding author address: Dr. Benjamin Pohl, Centre de Recherches de Climatologie, 6 boulevard Gabriel, 21000 Dijon, France.

E-mail: benjamin.pohl@u-bourgogne.fr between the Antarctic region and the southern midlatitudes. In the positive phase of the AAO, anomalous low (high) pressure occurs over Antarctica (the midlatitudes of the Southern Hemisphere). The midlatitude westerly winds and the upper-level subtropical jet also tend to be shifted toward the pole (the equator) during the positive (negative) phase of the AAO, in geostrophic balance with changes in the pressure field. These signals can be found throughout the year, with a possible seasonal peak in December (Gong and Wang 1999). The AAO is generally extracted as the first EOF of the sea level pressure or the geopotential height at some level 
(typically 850 or $700 \mathrm{hPa}$ ) for $20^{\circ}-90^{\circ} \mathrm{S}$, and the pattern is very similar whether daily, monthly, or seasonal anomalies are considered. The AAO has also been shown to present a significant trend toward the positive phase in recent decades (Jones and Widmann 2004), which can be only explained when external forcing related to stratospheric ozone depletion and increased atmospheric greenhouse gas concentration is taken into account (Thompson and Solomon 2002; Arblaster and Meehl 2006). Although some recent studies detailed its underlying physics and dynamics (e.g., Lorenz and Hartmann 2001; Codron 2005), the nature of the AAO variability still suffers from an incomplete description and understanding. At the interannual time scale, the variability of the AAO has been partly related to the El Niño-Southern Oscillation (ENSO) during the austral summer season (e.g., Carvalho et al. 2005; L'Heureux and Thompson 2006; Ciasto and Thompson 2008). L'Heureux and Thompson (2006) estimate that roughly $25 \%$ of the AAO variance linearly relates to the state of ENSO. Fogt and Bromwich (2006) more precisely depict significant relationships between these two phenomena during the 1980s and the 1990s for the December-February season, while for September-November significant teleconnections are only apparent during the 1990s. Seager et al. (2003) and Codron (2005) showed that ENSO anomalies can force the AAO and induce a significant part of its low-frequency variability. At the intraseasonal time scale, the fluctuations in the AAO have been related to the MaddenJulian oscillation (MJO) (Madden and Julian 1994; Zhang 2005) activity by Carvalho et al. (2005) and Matthews and Meredith (2004, hereafter MM04). The MJO is the dominant mode of atmospheric variability at the intraseasonal time scale and its periodicity typically varies between 30 and 60 days. It is mostly found at low latitudes, where it is associated with a mean eastward propagation of large-scale convective clusters $(\sim 10000 \mathrm{~km}$ across) from the Indian Ocean to the Maritime Continent of Indonesia and then to the west Pacific basin. Convective anomalies decay east of the warm pool, but the associated atmospheric dynamics (zonal wind, sea level pressure, and geopotential height in all layers of the troposphere) are consistent and highly significant at the near-global scale (Zhang 2005). The MJO modulates rainfall and surface pressure even in the mid and high latitudes (Donald et al. 2006). During the austral summer season, MJO signals extend into the southern subtropical latitudes [e.g., Australia (Wheeler and Hendon 2004, hereafter WH04) or South Africa (Pohl et al. 2007)] and significantly impact the midlatitude westerlies (MM04). Our aim here is (i) to reexamine the question of the statistical independence of the AAO, at both intraseasonal and interannual time scales, that is, to assess the nature of its relationship with the MJO and ENSO, and (ii), based on these results, to isolate the specific role of the AAO in rainfall variability at the regional scale. The regional example chosen here is southern Africa, a region under the influence of both the MJO (Pohl et al. 2007) and ENSO (Dyer 1979; Lindesay 1988; Reason et al. 2000).

\section{Data}

We use daily fields obtained from the National Centers for Environmental Prediction/Department of Energy (NCEP/DOE) Atmospheric Model Intercomparison Project (AMIP) II reanalyses (NCEP-2) (Kanamitsu et al. 2002): vertical component of the wind $(\omega)$ at $500 \mathrm{hPa}$ (class B field) (Kalnay et al. 1996), zonal and meridional components of the wind, $u$ and $v$, (class A fields) at various levels, and geopotential height at $700 \mathrm{hPa}$ (noted as hgt700 in the following) (class A field). Monthly sea surface temperatures (SST) are obtained from the Hadley Centre Sea Ice and Sea Surface Temperature (HadISST) dataset (Rayner et al. 2003), available on a $1^{\circ} \times 1^{\circ}$ regular grid for the 1979-2006 period. To assess the state of El Niño, the multivariate ENSO index (MEI) (Wolter and Timlin 1993), available since 1950 at the bimonthly time scale, has been used. This MEI is based on an empirical orthogonal function analysis applied to the multivariate combination of sea level pressure, zonal and meridional components of the surface wind, sea surface temperature, surface air temperature, and total cloudiness fraction of the sky over the tropical Pacific. This index is preferred to the usual SST-based indices because it better describes the coupled nature of ENSO. The MJO signal is captured by the real-time multivariate MJO indices developed by WH04. The indices are the principal component (PC) time series of the two leading EOFs of combined daily mean tropical (averaged $15^{\circ} \mathrm{N}-$ $\left.15^{\circ} \mathrm{S}\right) 850$ - and $200-\mathrm{hPa}$ zonal wind and outgoing longwave radiation (OLR) anomalies. WH04 subtracted the annual cycle and the low-frequency variability associated with ENSO before calculating the EOF. The indices, denoted real-time multivariate MJO 1 and 2 (RMM1 and RMM2), were designed to capture both the northern winter and summer MJO. RMM1 and RMM2 are approximately in quadrature and describe the average large-scale, eastward-propagating convective and circulation anomalies associated with the MJO. The evolution of the MJO can be concisely visualized in a twodimensional phase-space diagram, with RMM1 (RMM2) as the horizontal (vertical) Cartesian axes. WH04 divide the MJO pseudocycle into eight distinct phases, which depict the average eastward propagation of the convective and dynamic anomalies. For instance, convection 
starts over the Indian Ocean at phase 1. Large-scale convective clusters develop and extend over the Indian basin during phases 2 and 3 and reach the Maritime Continent during phases 4 and 5. In phases 6 and 7, they propagate over the west Pacific basin and are finally located in the Western Hemisphere and Africa during phase 8. Daily rainfall amounts over the Republic of South Africa are provided by the rain gauge records compiled in the Water Research Commission database by Lynch (2003). Out of 11000 stations, 7665, presenting no missing values, are extracted for the 1979-99 period; see Pohl et al. (2007) for the location of these stations. The large number and spatial coverage of these in situ records make it possible to investigate the spatial patterns of the AAO impact on rainfall over the country at both intraseasonal and interannual time scales and to avoid the use of satellite estimates. The AAO signal has been extracted in several ways in the literature. Gong and Wang (1999) and Meneghini et al. (2007) use the difference of normalized zonally mean sea level pressure between $40^{\circ}$ and $65^{\circ} \mathrm{S}$. Rogers and van Loon (1982) use the first EOF of a principal component analysis (PCA) applied to the sea level pressure over a domain extending south of $20^{\circ} \mathrm{S}$. Thompson and Wallace (2000) apply the same analysis on the same domain but on the $850-\mathrm{hPa}$ geopotential height. Carvalho et al. (2005), Reason and Rouault (2005a), L'Heureux and Thompson (2006), and Hendon et al. (2007), instead, use the 700-hPa geopotential height (hgt700) to determine the AAO. In this paper, to ensure that the results obtained are not biased by the choice of index, we use the methodology of Gong and Wang (1999) and that of Carvalho et al. (2005) and the papers cited above, and we verified that the choice of the AAO index does not qualitatively change any of our conclusions. Therefore, we follow the majority of recent work and adopt the methodology described, for instance, in Carvalho et al. (2005). Our daily AAO index is obtained as the leading principal component of an EOF analysis applied to the hgt 700 anomaly field south of $20^{\circ} \mathrm{S}$, after removal of the annual cycle, for the period 19792006. Each grid point was previously scaled by the square root of the cosine of its latitude. Our first EOF explains $27 \%$ of the original variance and shows a loading pattern (Fig. 1) very similar to that of Carvalho et al. (2005). A positive (negative) phase of the AAO index corresponds to above- (below-) average pressure over the Southern Ocean and below- (above-) average pressure over Antarctica. The highest loading is found above Antarctica (Fig. 1). Hence, fluctuations of geopotential height over this region are the most important to explain the AAO index variability. When averaged at the monthly time scale, our index shows more than $98 \%$ of common variance with the monthly AAO index available on the Cli-
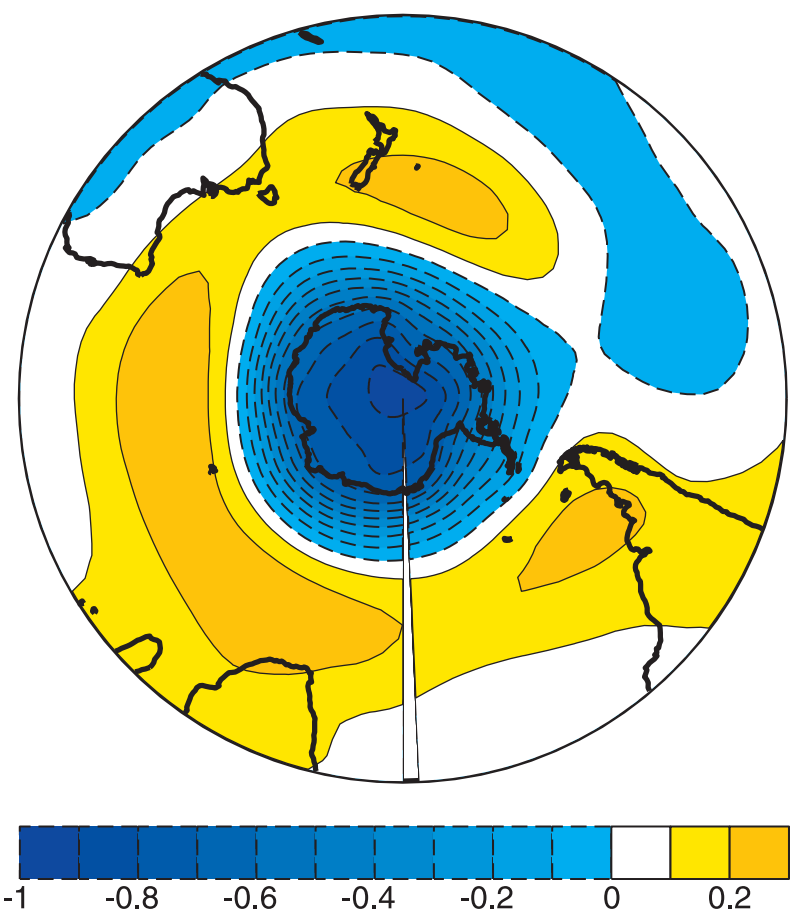

FIG. 1. Loading (correlation) pattern of the EOF analysis applied on the daily hgt700 field south of $20^{\circ} \mathrm{S}$ and after removal of the annual cycle for the period 1979-2006: Contour interval 0.1, negative correlations contoured with dashed lines. See text for details and legend for color shading.

mate Prediction Center (CPC) Web site, which is based on the same methodology (see http://www.cpc.noaa.gov/ products/precip/CWlink/daily_ao_index/aao/monthly.aao. index.b79.current.ascii.table).

\section{Results}

\section{a. Time scales of the $A A O$ variability}

The mechanisms responsible for the existence of the AAO have been related to eddy-mean flow interactions (Lorenz and Hartmann 2001; Codron 2005). The dominance and persistence of the AAO can be explained in terms of a positive feedback between the zonal wind and fluxes of transient eddy momentum. As such, the AAO (and more generally the annular modes in both hemispheres) seems to exhibit red noise behavior and to damp within 14-20 days (Feldstein and Lee 1998; Lorenz and Hartmann 2001). The AAO is then an internal mode of atmospheric variability; however, interactions with slowly varying boundary conditions and other modes of variability are likely to modulate the time scales of its variability (e.g., external forcing is responsible for the observed recent trend toward a more positive phase of the AAO).

To further document the AAO time scales of variability, which remain poorly documented to date, we 
TABLE 1. Average periodicity (days) and variance (\%) explained by the 13 intrinsic mode functions (IMF) of an empirical mode decomposition (EMD) analysis applied on the daily AAO index (i.e., the score time series of the EOF shown in Fig. 1) for the period 19792006. See text for details.

\begin{tabular}{|c|c|c|c|c|c|c|c|c|c|c|c|c|c|}
\hline & \multicolumn{13}{|c|}{ IMF } \\
\hline & 1 & 2 & 3 & 4 & 5 & 6 & 7 & 8 & 9 & 10 & 11 & 12 & 13 \\
\hline Periodicity (days) & 4 & 9 & 18 & 35 & 63 & 117 & 246 & 487 & 929 & 1703 & 4088 & 10220 & $+\infty$ \\
\hline Variance (\%) & 5.36 & 9.67 & 14.65 & 18.21 & 16.53 & 12.88 & 9.57 & 4.60 & 1.93 & 1.90 & 1.15 & 0.13 & 0.01 \\
\hline
\end{tabular}

applied an empirical mode decomposition (EMD) to the AAO index time series. The EMD has been introduced by Huang et al. (1998) for the analysis of 1D signals, in the context of time series analysis, as part of the HilbertHuang transform. The basic idea of the EMD is to allow for an adaptive and objective representation of the basic components of linear and nonlinear signals, and it is designed to accommodate nonstationarity in the series. In the application of the 1D EMD algorithm, the possible nonlinear signal, which may exhibit varying amplitude and local frequency modulation, is linearly decomposed into a finite number of mutually quasi-orthogonal, zero mean, frequency and amplitude modulated signals, called the intrinsic mode functions (IMF), as well as a residual function that (i) exhibits a single extremum, (ii) is a monotonic trend, or (iii) is simply a constant. Although the EMD is a relatively new data analysis technique, its power and simplicity have encouraged its application in many fields (see Huang and Wu 2008 for a review).

In the present case, $13 \mathrm{IMFs}$ were obtained to depict all fluctuations of the AAO index. Table 1 summarizes their mean frequency and associated variance. Each IMF is related to a percentage of the original time series variance, and the mean period of each IMF is obtained from the characteristics of the IMF as the ratio between two times the sample size $(2 \times N)$ and the number of zero crossings since the first condition that an IMF must satisfy is that the number of extrema (sum of minima and maxima) and the number of zero crossings must be equal or differ by one. We first note (Table 1 ) that the IMFs describing fluctuations longer than one year (IMF $8-13)$ explain only $10 \%$ of the overall variance. It is nonetheless the interannual component of the AAO that most previous work has analyzed. For our study period, long-term trends only account for $0.14 \%$ of the overall variance of the AAO time series (IMF 12 and 13). This result could be due to the relatively short time series (28 years). Hence, the time series were not detrended in the following analysis. The high frequency range (subsynoptic and synoptic variability, that is, frequencies less than two weeks) only accounts for $15 \%$ of the overall AAO variance. The highest frequencies probably correspond to atmospheric noise without inducing mass transfer between Antarctica and the midlatitudes. IMF
3-6 (4 and 5) represent more than $62 \%$ (34\%) of the variance, concentrating between 18 and 117 (35 and 63) days. They describe the intraseasonal time scale, the 35-63-day range being reminiscent of the MJO. This result leads us to investigate the possible relationships between the MJO and AAO.

\section{b. Relationships with the MJO}

Figure 2a presents a composite analysis of the AAO index for the different phases of the MJO cycle. A more exhaustive description of the phases can be found in WH04 and section 2. During phase 3 (6), the AAO index shows significant negative (positive) anomalies, describing on average anomalously high (low) pressure over Antarctica and low (high) pressure over the surrounding ocean. During these phases, the large-scale convective clusters associated with the MJO are located over the Indian (west Pacific) Ocean. The fluctuations of the AAO index over the MJO cycle remain weak with values ranging from -0.1 to 0.15 (representing an amplitude of 0.25 standard deviation between the two opposite phases). This questions the statistical significance of the relationship between the two oscillations. To further investigate the relationships between the two signals, a cross-spectrum analysis is applied to the AAO index and the first EOF of WH04, RMM1, used here as a single indicator of the global-scale MJO activity (Fig. 2b). The same results can be obtained with the second EOF RMM2, but the phase relationship in the cross-spectrum analysis is shifted with a value of $\pi / 2$ radians (not shown). In the intraseasonal range (roughly 20-120 days), the two time series show a very weak association. The coherence squared, indicating their common variance for each frequency, remains lower than $5 \%$. The phase relationship is not constant, varying between $\pi / 2$ and $3 \pi / 2$. Paradoxically, significant results are only obtained at the subsynoptic time scale, with a peak of coherence squared at $12 \%$ for a period of 4 days (Fig. 2b). Additional analyses (not shown) reveal that these results are not seasonally dependent.

These results raise concerns about the nature of the relationship between the MJO and the AAO. Two studies (MM04; Carvalho et al. 2005) have recently presented the case for these two modes being related. 

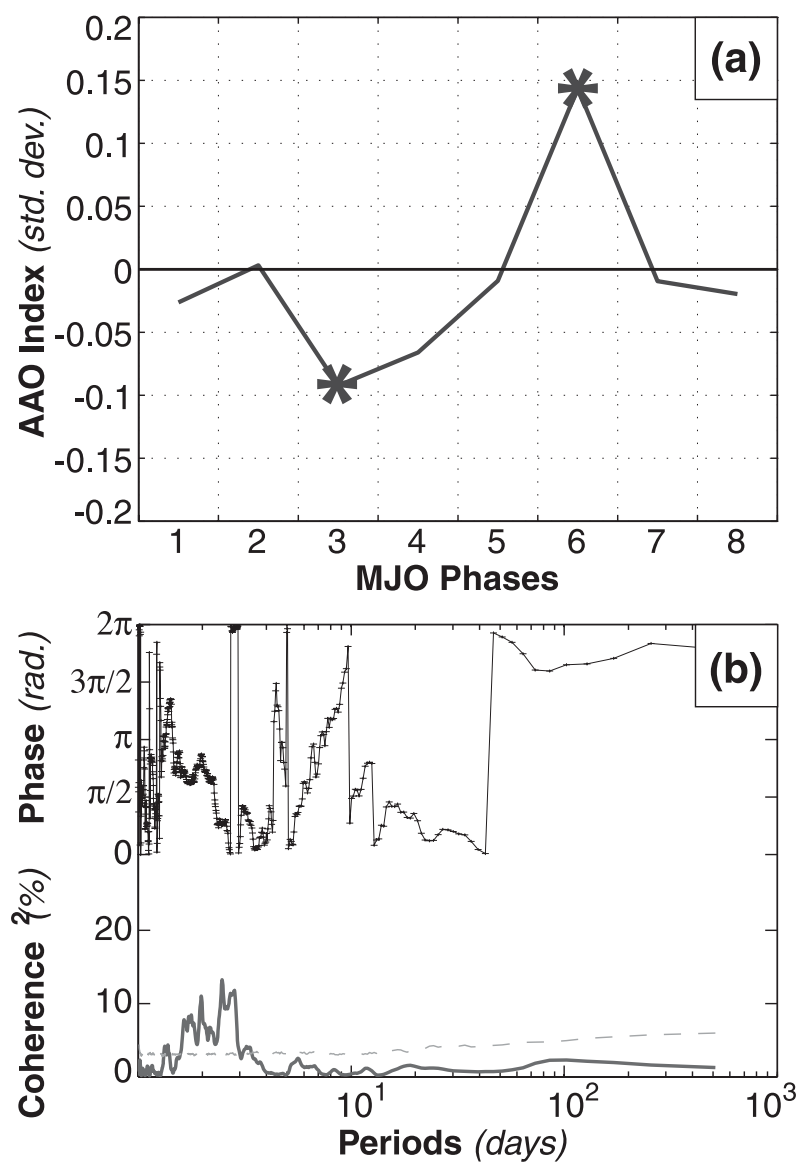

FIG. 2. (a) Composite analysis of the AAO index for the eight MJO phases defined in WH04. Asterisks show significant anomalies. (b) Cross-spectrum analysis of the AAO index and the MJO index RMM1 defined in WH04. All analyses are carried out on normalized data for 1979-2006. Gray lines: square coherence. Dashed lines indicate the $95 \%$ level according to 1000 random time series obtained as permutations of the original time series, and having the same lag-1 serial correlation. Solid black line: phase relationship in radians.

MM04 deals with the impact on the oceanic circumpolar transport and the westerly fluxes near Drake Passage during the Southern Hemisphere winter. Carvalho et al. (2005) is based on only the opposite phases of the AAO in summer, defined as the excesses over one (below minus one) standard deviation, and suggests that the triggering of positive and negative phases of the AAO is related to eastward propagating convective patterns in the tropics reminiscent of the MJO. However, both studies infer relationships based on lagged OLR patterns without making use of an index that strictly extracts the MJO-related convective variability.

Two hypotheses can be formulated to explain the weakness of the relationship between the MJO and AAO. (i) The influence of the MJO on the high southern latitudes could be weak and not significant. Such a hy-

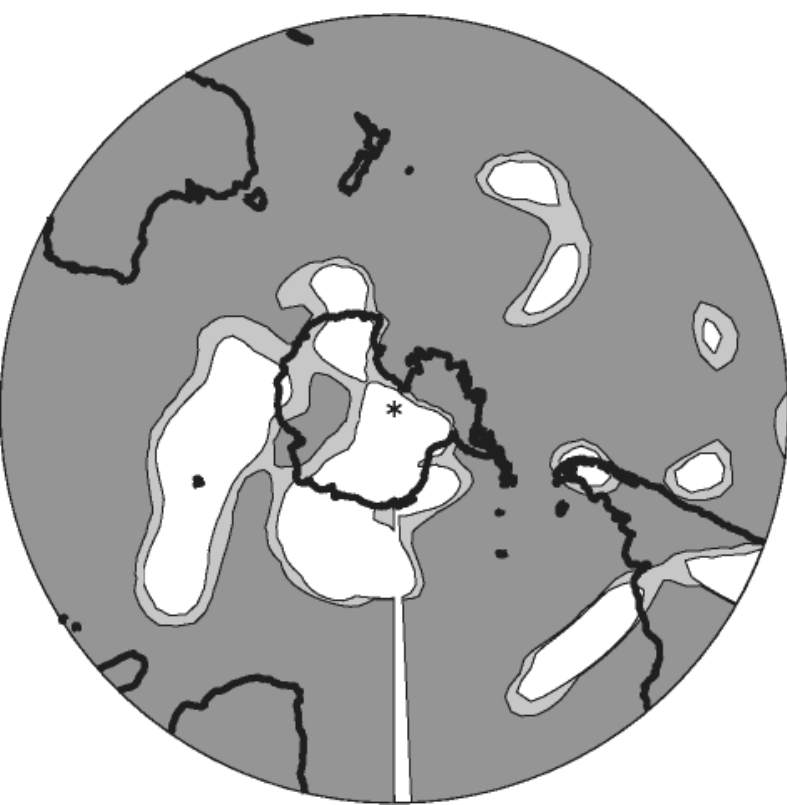

FIG. 3. Analysis of variance between the daily hot700 anomalies and the eight MJO phases defined in WH04. Light (dark) gray correspond to the $95 \%$ (99.9\%) confidence bound.

pothesis is unlikely, the consistence of the MJO signal in this domain being demonstrated in MM04. (ii) Even if significant, the influence of the MJO at these latitudes could be unrelated with coherent and zonally symmetric mass transfer between Antarctica and the circumpolar ocean; that is, MJO-associated anomalies (in the geopotential field, for instance) might not be annular and the apparent relationships could be related to an imperfect projection of the regional signature of the MJO onto the AAO pattern as displayed in Fig. 1.

To verify these hypotheses, the spatial pattern of the MJO in the high southern latitudes is now examined to assess its significance. Figure 3 displays the results of an analysis of variance computed between the daily hgt700 grid points, used to compute our AAO index, and the eight MJO phases defined in WH04. The significance of the MJO signal in the Southern Hemisphere is obvious, most areas reaching the $99 \%$ level. Such results are in accordance with MM04 and lead us to reject hypothesis (i).

The mass transfer associated with the MJO in the Southern Hemisphere could thus be involved. Figures 4 and 5 present the geopotential height and wind anomalies at $700 \mathrm{hPa}$ over the MJO life cycle. The same analyses applied to the surface fields lead to the same results. In spite of some regional differences, the wind and geopotential anomaly patterns are not strongly affected by the seasonal cycle (not shown).

Schematically, all hgt700 anomaly patterns show the well-known zonal dipole associated with the MJO and 

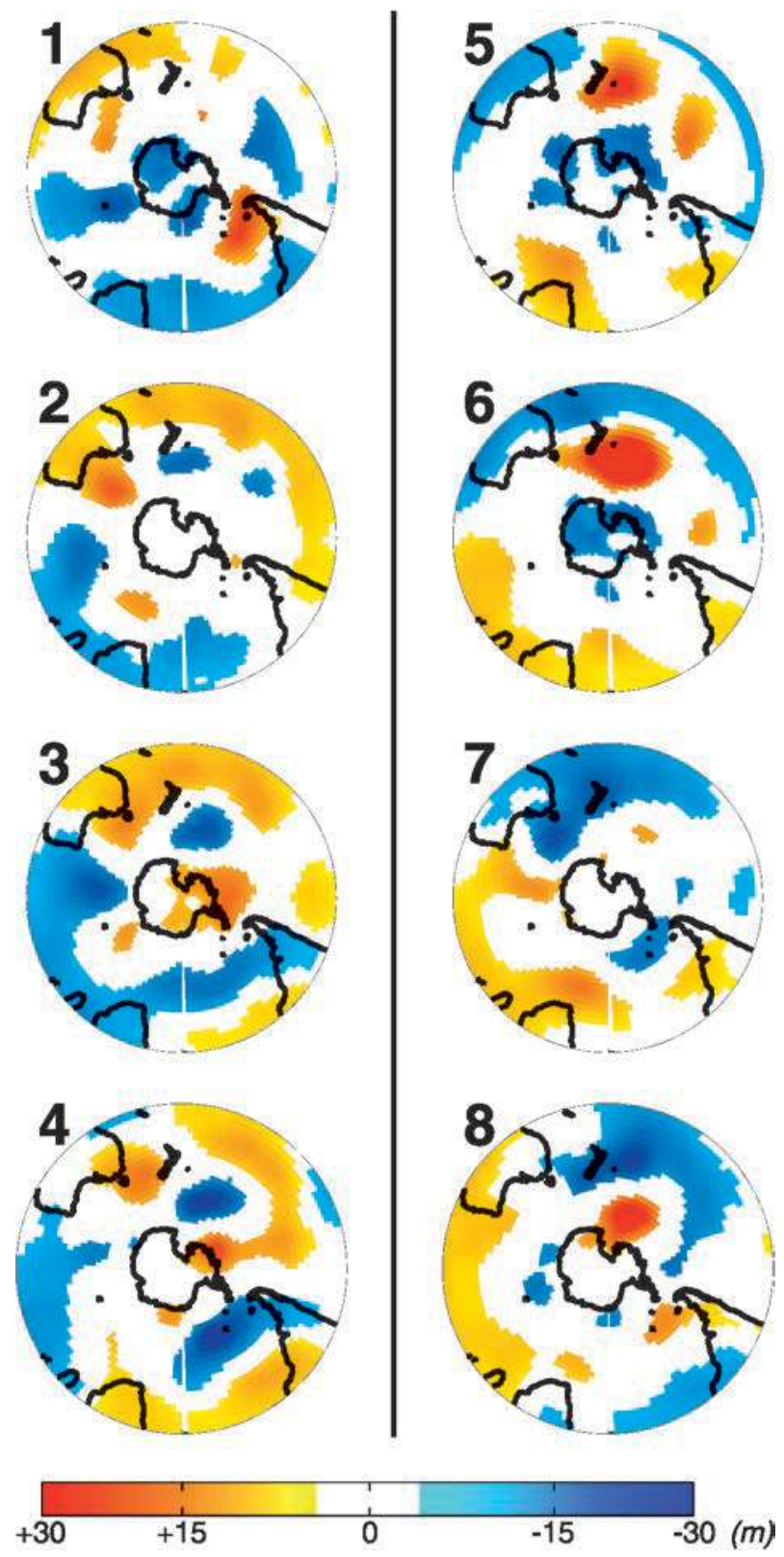

FIG. 4. Composite hgt700 anomalies for the eight MJO phases defined in $\mathrm{WH} 04$. Anomalies that are not significant at the $95 \%$ level according to a $t$ test are shaded white. See legend for the color shading.

propagate eastward with time (Fig. 4). Anomalies are remarkably consistent in the southern midlatitudes. The negative hgt700 anomalies are locked on the MJOassociated convective clusters: at phases 2-3 they are located over the Indian Ocean and then reach the Maritime Continent at phases 5-6 before migrating over the west Pacific basin at phases 7-8 and crossing the Atlantic Ocean and Africa at phase 1 . Such a description is roughly in agreement with the OLR anomalies in
WH04. The positive hgt700 anomalies, corresponding to suppressed convection, are generally observed with a $180^{\circ}$ longitudinal shift. These patterns correspond to the MJO wavenumber- 1 characteristics. Instead of an annular hgt700 pattern, Fig. 4 basically depicts these eastwardpropagating opposite-signed features between the two longitudinal hemispheres.

Over Antarctica, the geopotential height anomalies are weaker and spatially less consistent. They are positive during phase 3 and negative during phases 5, 6, and 1 . However, anomalies of opposite signs between the continent and the surrounding ocean are only observed during phases 3 and 6, which explains the significant AAO index anomalies (Fig. 2a). Even during these two key phases, it is, however, not possible to identify a zonally symmetric pattern indicative of a generalized mass transfer.

The same statement is also true for the wind fields (Fig. 5). The MJO is never associated with a continuous enhancement of the midlatitude westerlies at all longitudes, a result that already appeared in the analyses of MM04. Its effects mainly consist of regional-scale cyclonic or anticyclonic anomalies that tend to propagate eastward. Once again, these patterns illustrate the absence of MJO-related annular signals in the wind.

In short, the average MJO life cycle in the mid and high southern latitudes is not associated with a zonally symmetric and extensive mass transfer between Antarctica and the circumpolar ocean. Hence, MJO and AAO do not seem to interact on average, and their fluctuations show no clear and constant phase locking. These findings differ from those of previous studies (MM04; Carvalho et al. 2005). One possible reason is that the methodology used here has more exhaustively described the phase relationship and the common variance between the descriptors of both signals. The results shown in MM04 were essentially based on the intraseasonal variations in the westerlies without directly considering the overall mass transfer with Antarctica. The results of Carvalho et al. (2005) were only based on the extreme values of the AAO index. As such and in relation to the prominent weight of the Antarctic continent in the determination of the EOF (Fig. 1), nonzonally symmetric anomalies can project in the first EOF and be responsible for extremes in the associated principal component.

\section{c. Relationships with ENSO}

Several papers (cited above) depict a significant association with ENSO during the austral summer season. Figure 6a presents the annual cycle of the correlation values between the seasonal mean MEI and the AAO index, calculated with a moving 4-month window. The period from November through February (NDJF) 

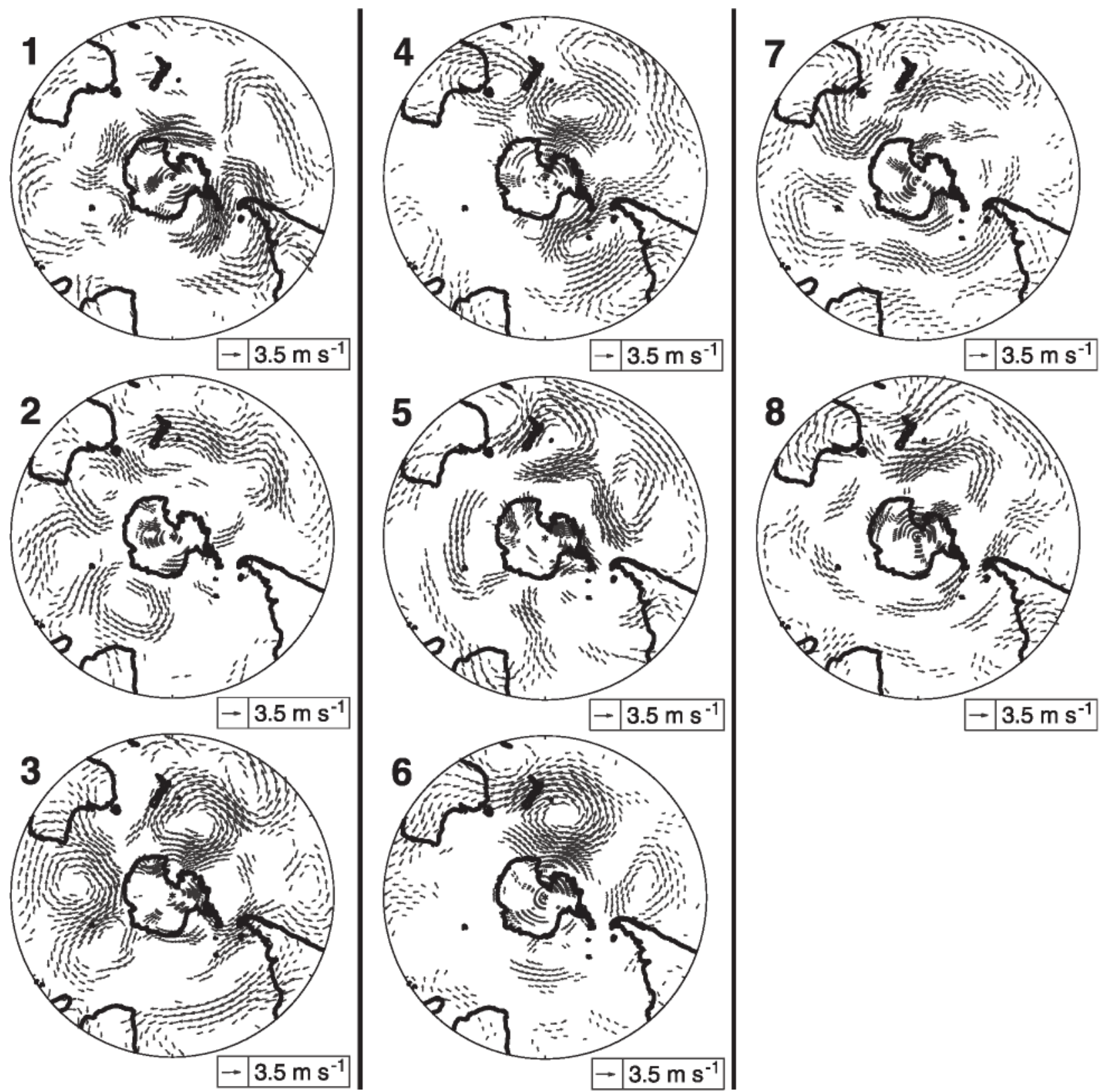

FIG. 5. Composite wind anomalies at $700 \mathrm{hPa}$ for the eight MJO phases defined in WH04. Only anomalies significant at the $95 \%$ level according to a Hotelling $t^{2}$ test are shown on the figure.

appears as the only season of the year, reaching the $95 \%$ and even the $99 \%$ significance levels. The negative sign of the correlations indicates that El Niño (La Niña) events tend to coincide with the negative (positive) phase of the AAO, a result consistent with previous work and confirmed by Fig. $6 \mathrm{~b}$. The common variance between the two indices peaks at $28 \%$ during this season. Though rather weak, and not significant, the correlations for boreal summer are of reversed (positive) sign.

Figures $6 c-e$ specifically focus on the case of NDJF. Figure $6 \mathrm{c}$ shows the signature of ENSO in hgt700, that is, the input field from which the AAO index is derived. El Niño is associated with higher than normal seasonal pressure and geopotential height over Antarctica and lower ones over the Southern Ocean. As stated in L'Heureux and Thompson (2006), the ENSO pattern projects very well onto the AAO spatial signature with an apparent annular pattern at the midlatitudes. Symmetrically, Fig. $6 \mathrm{~d}$ presents the teleconnection pattern between the seasonally averaged AAO index and the global-scale mean SST field during the same period of the year. Over the Southern Hemisphere, the SST field 


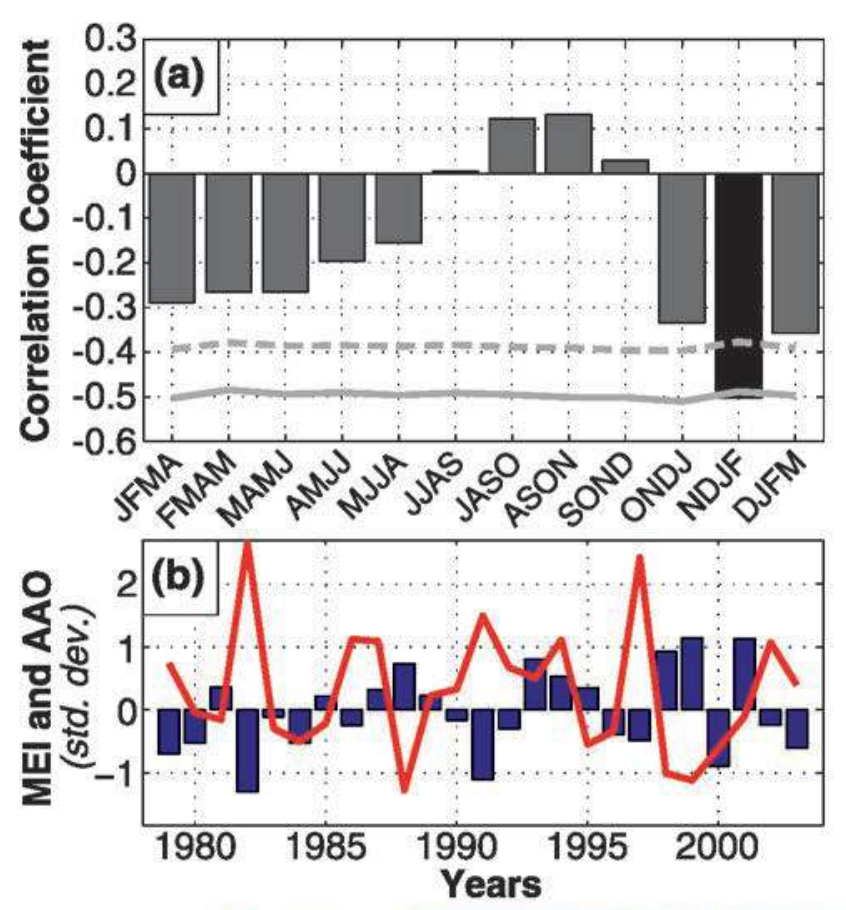

(c)
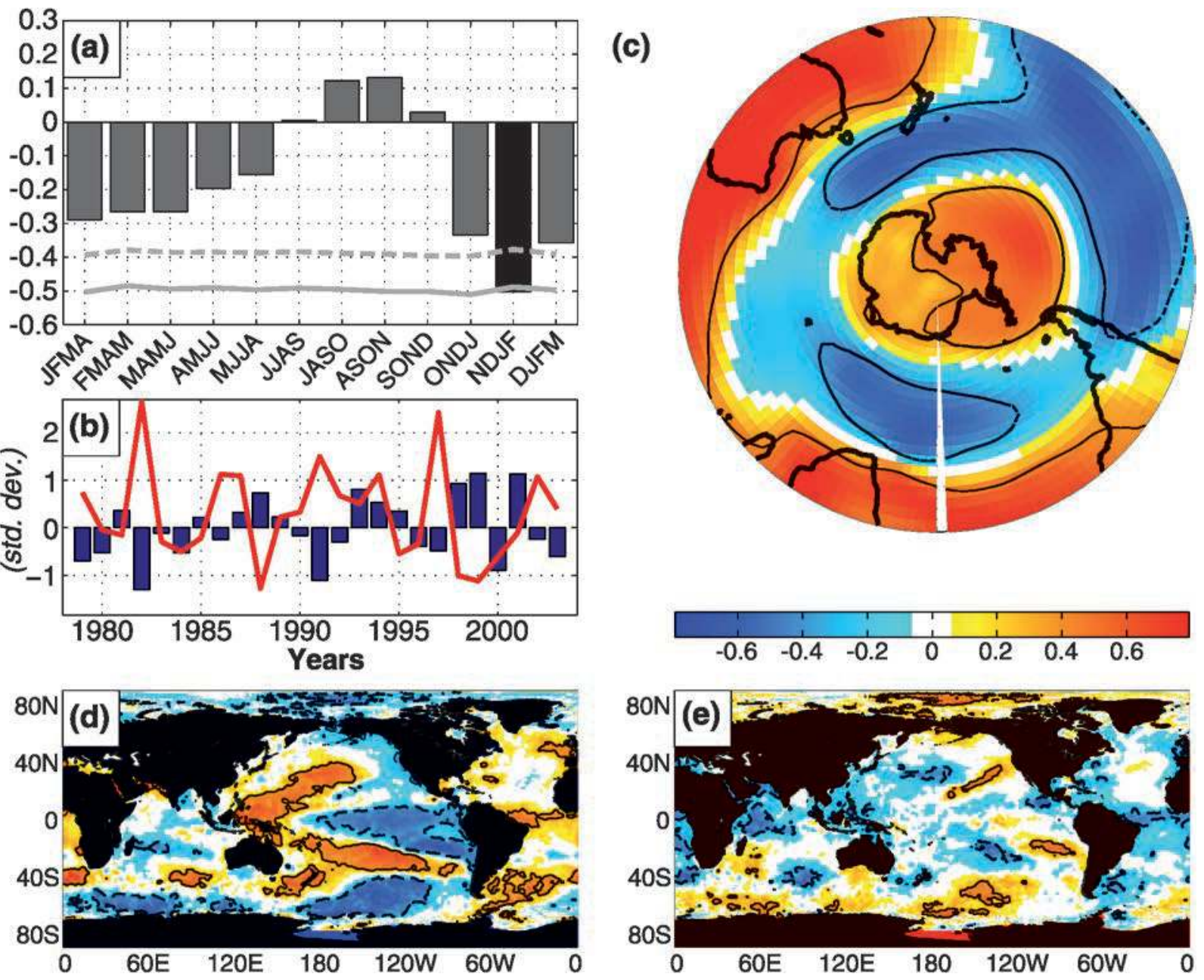

FIG. 6. (a) Annual cycle of the correlation between MEI and AAO. The two indices were seasonally averaged on a 4-month-long moving window [i.e., Jan-Apr (JFMA), Feb-May (FMAM), . , , Dec-Mar (DJFM)] to smooth the time series. Significant correlations at the $95 \%$ level appear in black. (b) Time series of the seasonal mean MEI index (red curve) and AAO index (bars) for the NDJF season 1979-2006. (c) Correlation field between the seasonal mean MEI and the hgt700 field for NDJF 1979-2006. Significant positive (negative) correlation values at the $95 \%$ level are contoured with a solid (dashed) line. See legend for color shading. (d) Teleconnection pattern between the seasonal mean AAO index and the corresponding sea surface temperature grid points for NDJF 1979-2006. Significance tested and represented as for (c). See legend for color shading. (e) As in (d) but for partial linear correlations after removal of the variance associated with the seasonal mean MEI. Significance tested and represented as for (c).

shows a significant and physically consistent response to the AAO, with a negative (positive) correlation annular pattern found in the southern high (mid) latitudes. In the tropics, the teleconnection pattern is clearly reminiscent of ENSO with negative correlation values in the eastern Pacific and horseshoe-shaped positive ones in the western Pacific. Partial correlations calculated after removal of the variance associated with the synchronous MEI (Fig. 6e) - that is, teleconnections between the seasonal mean AAO and SST grid points after removing the effects of ENSO-fully confirm the implication of the latter. The two annular patterns observed in the mid and high latitudes of the Southern Hemisphere are also dramatically weakened and are therefore partly related to ENSO.

Considering monthly fields provides, however, a different image of the AAO-ENSO relationship (Fig. 7), which has been neglected to date. The seasonal cycle of the relationship between the two phenomena is much less smoothed than that obtained with seasonal mean fields (Fig. 6a). The statistical relationship between AAO and ENSO during austral summer becomes barely significant here for the individual months of the NDJF season. The high correlation values obtained in Fig. 6 are mostly attributed to the months of November, and to a lesser extent December and January, that is, the peak 


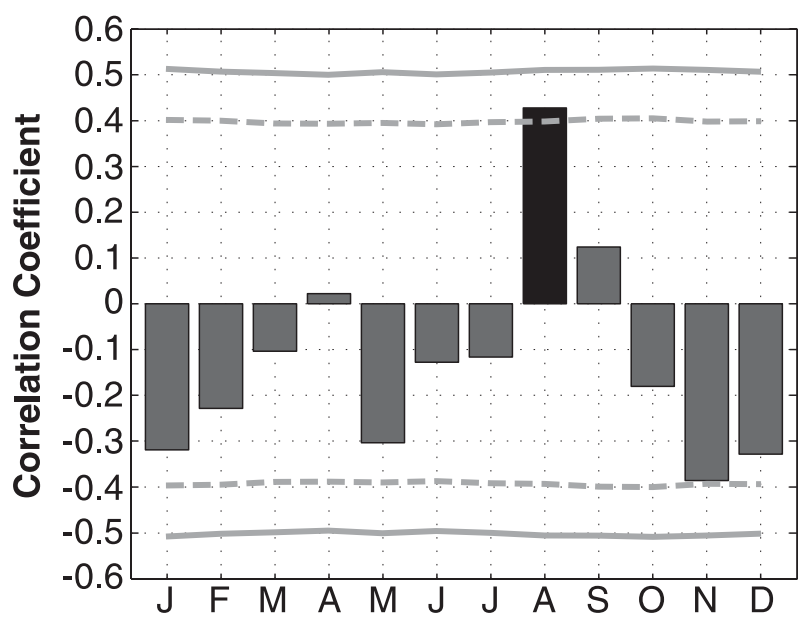

FIG. 7. Annual cycle of the correlation between MEI and AAO monthly indices. Significant correlations at the $95 \%$ level appear in black.

of El Niño anomalies. The only month reaching the $95 \%$ confidence bound is August, with a positive correlation value that explains the reversed sign of the correlations for boreal summer. Given the relatively weak El Niño activity at this time of the year and the absence of a significant relationship for the months of July and September, its physical robustness is questionable. One possible reason for these differences with seasonally averaged indices involves the month-to-month autocorrelation of the AAO index, which is far less than that of ENSO indices (including the MEI).

Figure 8 shows the spatial signature of ENSO in the hgt700 field for the 12 months of the year. The annular nature of its associated pattern and the opposite-signed anomalies between Antarctica and the surrounding ocean are both less obvious. Over Antarctica, positive geopotential height anomalies develop in October but are centered on the pole during November and December only. They rapidly decay between January and March. During these months, negative anomalies occur over the Southern Ocean but without annular patterns. The anomalies weaken in June and July and then change sign. Negative anomalies over Antarctica are found in August and September, together with located positive anomalies over the ocean that are not of annular nature.

The rather strong relationships established in previous papers between ENSO and the AAO appear to be mainly relevant to the geopotential height anomalies over the continent, in accordance with the AAO spatial pattern (Fig. 1). They are only significant when seasonal mean fields are considered and only during the NDJF season. Caution must be exercised when working on the austral summer season, as AAO and ENSO may interfere. Consequently, in order to avoid biased predictions or spurious diagnostic results, it is necessary to isolate the respective influence of both phenomena. To address this issue, we focus next on the influence of the AAO on the rainfall field, at both interannual and intraseasonal time scales. The example chosen here is southern Africa, a region under the influence of ENSO (Reason et al. 2000) and whose main rainy season is in NDJF.

\section{d. Consequences for rainfall analysis: The example of South Africa}

In this section, our aim is to illustrate how to separate or discriminate the impacts of different "major" modes of climate variability when they are not statistically independent, that is, when they show significant common variance. Thus, we try to quantify the specific role of the $\mathrm{AAO}$ on a given area during austral summer without the interference from ENSO signals.

Our choice of southern Africa (SA) as a case study was motivated by four reasons. (i) As stated above, most parts of this region experience heavy rainfall during the austral summer season except for the Western Cape Province where winter rainfall dominates. (ii) The role of ENSO on the regional climate variability is quite well documented (Dyer 1979; Lindesay 1988; Reason et al. 2000) and its influence is significant, especially since the 1970s (Richard et al. 2000, 2001). The region is also affected by the MJO (Pohl et al. 2007), the variability of the latter being unrelated to that of the AAO (section 3b). (iii) The role of the AAO on summer rainfall variability has only been touched on very briefly [Reason and Rouault (2005b); see as well Fig. 8 in Jones and Widmann (2003)], and the time scale at which this influence is detectable is still questionable. However, Reason and Rouault $(2005 \mathrm{a}, \mathrm{b})$ pointed out a significant relationship between the AAO and winter rainfall interannual fluctuations in the Western Cape Province, suggesting that the AAO may also have an influence on the other parts of the country during the summer rainy season. (iv) SA has a relatively dense network of in situ rainfall measurements, making it possible to avoid the use of satellite estimates. Note that SA here means the Republic of South Africa plus a few stations in the bordering countries of Lesotho, Swaziland, southern Botswana, Namibia, and Mozambique.

\section{1) INTERANNUAL TIME SCALE}

The interannual time scale is first considered. Figure 9 shows the total and partial correlations between the seasonal mean MEI and AAO indices and the seasonal SA rainfall amounts in NDJF. Figure 10 presents the same correlations with the 850 - and $200-\mathrm{hPa}$ horizontal wind and midtropospheric vertical velocity. In this section, the $850-\mathrm{hPa}$ level is preferred to $700 \mathrm{hPa}$ because of 

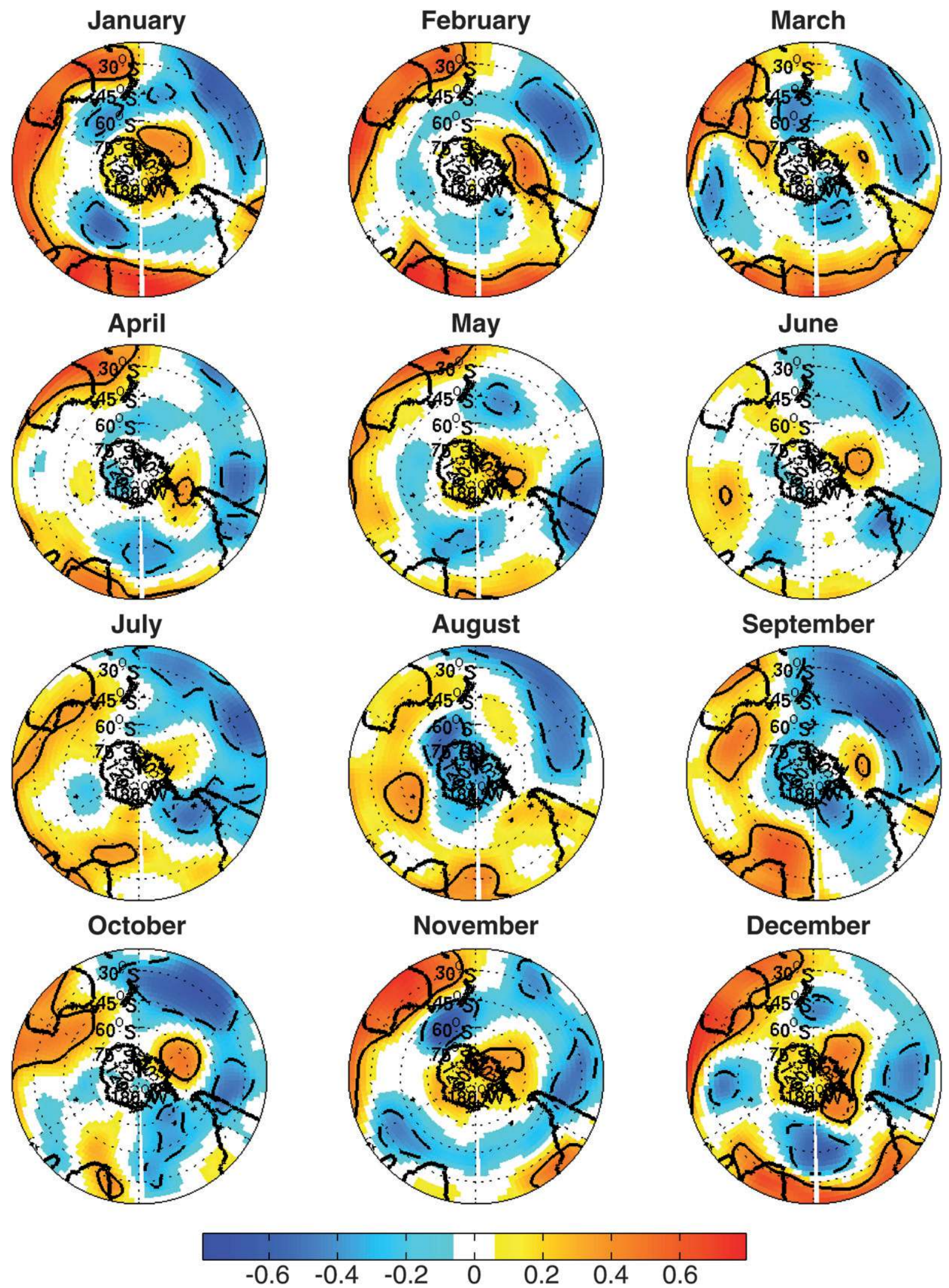

FIG. 8. Correlation field between the monthly mean MEI and the hgt700 field for each month of the year from 1979 to 2006 . Significant positive (negative) correlations at the $95 \%$ level are contoured with a solid (dashed) black line. See legend for color shading. 

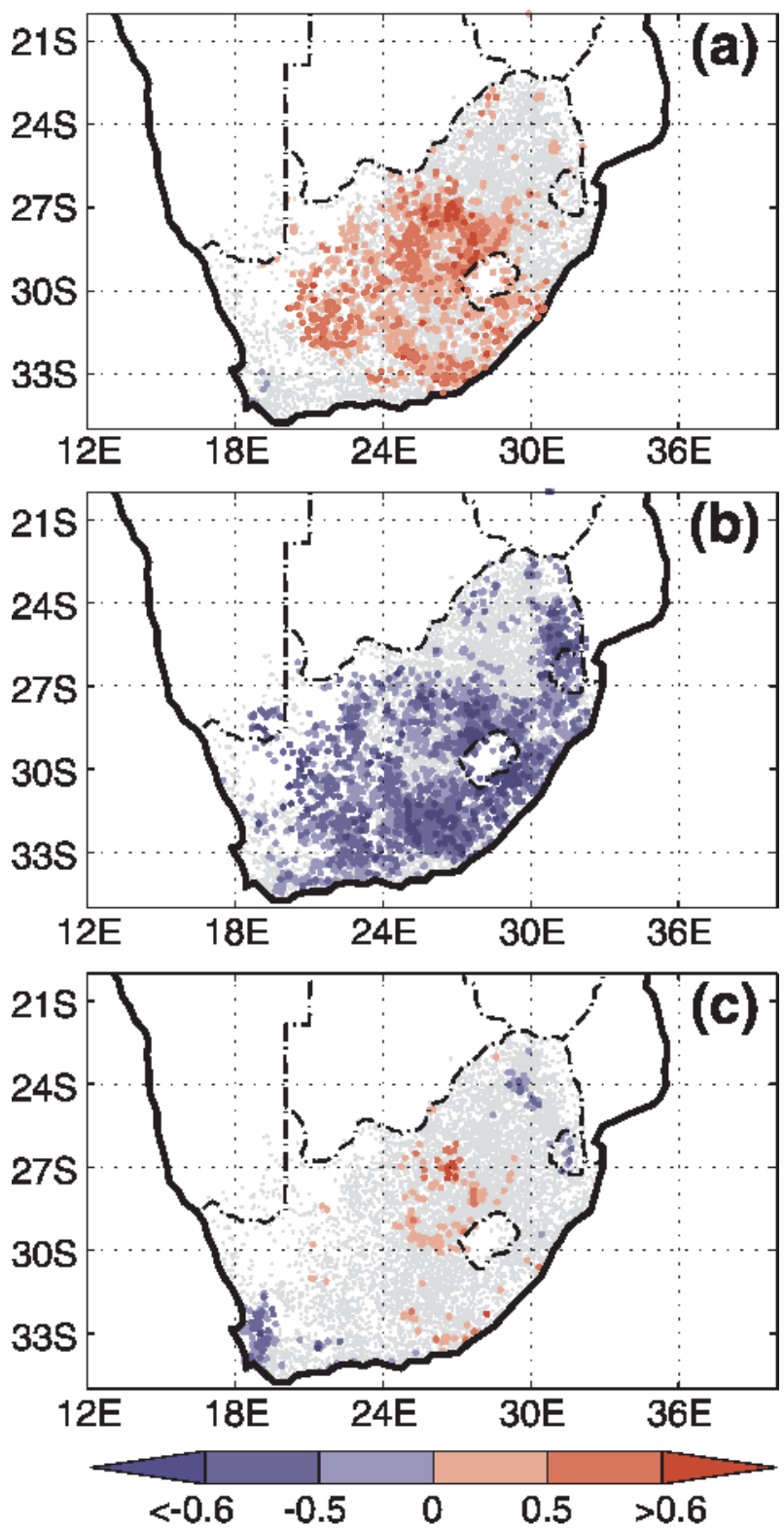

FIG. 9. (a) Correlation between the AAO seasonal mean index and the rainfall seasonal amount in each rain gauge station of southern Africa for NDJF 1979-99. See color legend for the correlation values; correlations that are not significant at the $95 \%$ level are shaded gray. (b) As in (a) but for the seasonal mean MEI. (c) As in (a) but for partial correlations with the seasonal mean AAO index, after removal of the variance of the seasonal mean MEI.

its stronger importance in conveying moisture toward the region.

From one year to another, the AAO has an apparent strong influence on the SA region. Positive phases of the AAO (i.e., low pressure anomalies over Antarctica and high ones over the Southern Ocean) correspond to higher than average rainfall amounts over central SA (Fig. 9a), a southward shift of the westerly winds (Figs. 10a,b), and ascending motion anomalies in the midtroposphere (Fig. 10c). This signal in the vertical component of the wind can be found at all layers of the troposphere, indicating that deep convection is involved and favored over the region by the positive phase.

The influence of ENSO is shown in Figs. $9 \mathrm{~b}$ and 10d-f. Its effects on rainfall are similar to those of the AAO, in terms of spatial extent and intensity of the correlations (Fig. 9), but are of opposite sign. El Niño events correspond to regional-scale drought (Fig. 9b) and subsiding motion over a large area extending from Botswana to the southwest of Madagascar (Fig. 10f). These signals are found from the surface to the tropopause, confirming the deep convective nature of the processes. Northern SA is also affected by these subsiding anomalies, but El Niñoassociated droughts clearly extend over a larger area than the region appearing in Fig. 10f (e.g., Fauchereau et al. 2009). Hence, the correspondence between SA rainfall and NCEP-2 vertical velocity is not perfect, even at these rather low frequencies. Positive lower-layer geopotential height anomalies are found over SA during El Niño years (Fig. 6c). Hence, the weakening of the westerlies over the Atlantic near $50^{\circ} \mathrm{S}$ (Figs. 10d,e) can be explained as quasigeostrophic wind anomalies. On the contrary, near the equator and over the central Indian Ocean (equatorial and subtropical latitudes) ascending motion tends to prevail, in agreement with previous studies (e.g., Beltrando and Cadet 1990; Hastenrath 2000; Black et al. 2003). This meridional opposition is at the origin of the convective dipole observed at the interannual time scale over the east coast of southern Africa (Fauchereau et al. 2009).

The partial correlations between the SA rainfall and the AAO index, after removal of the effects of ENSO, reveal a dramatic weakening of the statistical relationship (Fig. 9c). The AAO appears here to be, in fact, weakly involved in the rainfall interannual variability, the large scores obtained in Fig. 9a being largely due to the interference with ENSO during this season (section $3 \mathrm{c})$. Over SA, the AAO describes a tripolar pattern, the center of the country showing opposite signals compared to the extreme northeast and the extreme southwest (this latter area, the Western Cape, typically experiences dry conditions in NDJF). Very few rain gauge stations show significant relationships with the interannual component of the AAO. Correlations with the vertical wind at $500 \mathrm{hPa}$ (Fig. 10i) and horizontal wind (Figs. 10g,h) are also weakened compared to Figs. 10a-c, demonstrating again the implication of ENSO. Over the southern Atlantic, correlations with both lower- and upper-layer wind remain significant nonetheless, indicating that ENSO and AAO are liable to add or cancel their effects according to 

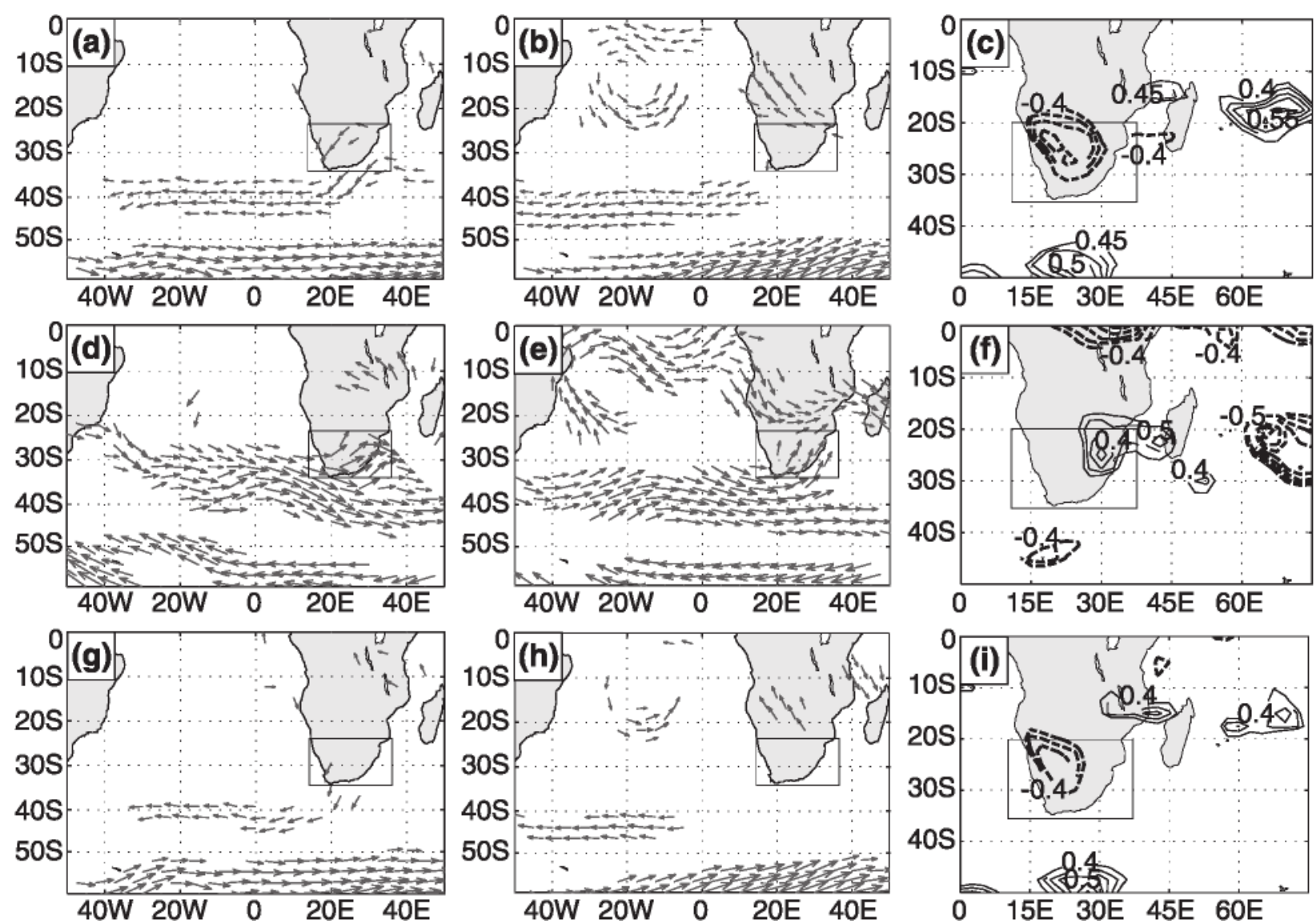

FIG. 10. (a) Correlation between the AAO seasonal mean index and the seasonal mean horizontal wind at $850 \mathrm{hPa}$ for NDJF $1979-2006$. Only correlations significant at the $95 \%$ level are shown on the figure. The black box corresponds to the region shown in Fig. 9 , for which in situ rainfall records are available. (b) As in (a) but for the 200-hPa level. (c) As in (a) but for the seasonal mean of the vertical component of the wind at $500 \mathrm{hPa}\left(\mathrm{Pa} \mathrm{s}^{-1}\right)$. Only correlations significant at the $95 \%$ level are shown on the figure; contour interval is 0.05 . Negative (positive) correlations are contoured with dashed (solid) lines. (d)-(f) As in (a)-(c) but correlations calculated with the seasonal mean MEI. (g)-(i) As in (a)-(c) but for partial correlations with the seasonal mean AAO index after removal of the variance of the seasonal mean MEI.

their respective state when they do not fluctuate in phase. For instance, El Niño and the negative phase of the AAO add their effects and favor strong (weak) westerlies near $40^{\circ} \mathrm{S}\left(55^{\circ} \mathrm{S}\right)$. The reverse is true for La Niña and the positive phase of the AAO.

In summary, the AAO is only weakly involved in the SA summer rainfall interannual variability, which is mostly related to ENSO. However, their common variance remains moderate and both modes can fluctuate on their own. The lack of clear relationship between AAO and SA rainfall could also conceal a more marked influence at the intraseasonal time scale, which will be examined in the following section.

\section{2) INTRASEASONAL TIME SCALE}

Our aim here is to describe the intraseasonal behavior of the AAO, shown to be rather energetic (Table 1), and its impacts on SA rainfall. To avoid interference with
ENSO, three distinct groups of years (El Niño, neutral, and La Niña years) were identified. The 25th and 75th percentiles of the seasonal mean MEI were used as threshold values. For each group the opposite phases of the daily AAO index are then extracted. Following Carvalho et al. (2005), the positive (negative) phase is defined as a daily index value above (below) one (minus one) standard deviation.

As a consequence of the AAO-ENSO teleconnection during austral summer (Fig. 6), found at the interannual time scale, the frequency of the positive and negative phases of the AAO at the daily time scale could also be affected by the state of El Niño. Table 2 aims to clarify this point. El Niño (La Niña) years indeed show negative (positive) seasonal values of the AAO index, and the difference between these two groups of years is significant at $95 \%$ according to a $t$ test. The standard deviation of the daily index time series during the three groups of 
TABLE 2. Seasonal mean, standard deviation, and frequency (\%) of the positive $(>1)$ and negative $(<1)$ phases of the daily AAO index for El Niño, neutral, and La Niña years. See text for definitions.

\begin{tabular}{lrrrr}
\hline & \multirow{2}{*}{$\begin{array}{c}\text { Mean } \\
\end{array}$} & Std dev & \multicolumn{2}{c}{ Percentage of days: } \\
\cline { 4 - 5 } & AAO & AAO & AAO $>1$ & AAO $<-1$ \\
\hline El Niño & -0.21 & 1.00 & $10.67 \%$ & $24.33 \%$ \\
Neutral & 0.02 & 0.77 & $7.83 \%$ & $9.33 \%$ \\
La Niña & 0.11 & 0.81 & $13.33 \%$ & $9.42 \%$ \\
\hline
\end{tabular}

years is very similar and is not related to ENSO. In other words, the high-frequency component of the AAO is as energetic in El Niño conditions as in La Niña. The probabilities of the daily opposite phases of the AAO also appear are strongly modulated by ENSO. El Niño years are particularly characterized by a very high probability $(24 \%)$ of the negative AAO phases. The reverse situation (positive phases in La Niña years) is less clear. This statement could be due to the fact that the negative phase is temporally much more persistent than the positive phase (Carvalho et al. 2005).

The implication for our composite analyses is that the two samples corresponding to the opposite phases of the daily AAO index have a dissimilar size during El Niño and, to a lesser extent, La Niña conditions (Table 2). Statistically this issue is not a problem, as the sample size is taken into account in the two-tailed Student's $t$ test used to test the significance of the El Niño and La Niña composites. In the following, the composite analyses between the opposite phases of the AAO are applied to the SA rainfall and wind anomalies for the distinct groups of years discussed above. Although each group is by construction homogeneous interannually, they still present a small year-to-year variability, which was removed by subtracting the seasonal mean daily rainfall amount for each year individually. Hence, the resulting time series present only subseasonal variability. The results are shown in Figs. 11 and 12.

During El Niño conditions (Figs. 11a and 12a-c), the influence of the AAO on the intraseasonal rainfall variability is limited. The Western Cape and the center of South Africa are the main areas affected, and the difference in the daily amounts between the opposite phases of the AAO is mainly between 1.5 and $3 \mathrm{~mm} \mathrm{day}^{-1}$. Significance is reached at a relatively low number of stations. During these years, the opposite phases of the AAO are not accompanied by clear dynamical signals over the region (Figs. 12a-c). The opposite phases of the AAO only modify the location of the midlatitude westerlies without inducing clear mass convergence over Africa in either the lower or upper troposphere.

The impact of the AAO notably strengthens during neutral years (Figs. $11 \mathrm{~b}$ and $12 \mathrm{~d}-\mathrm{f}$ ). Interestingly, the
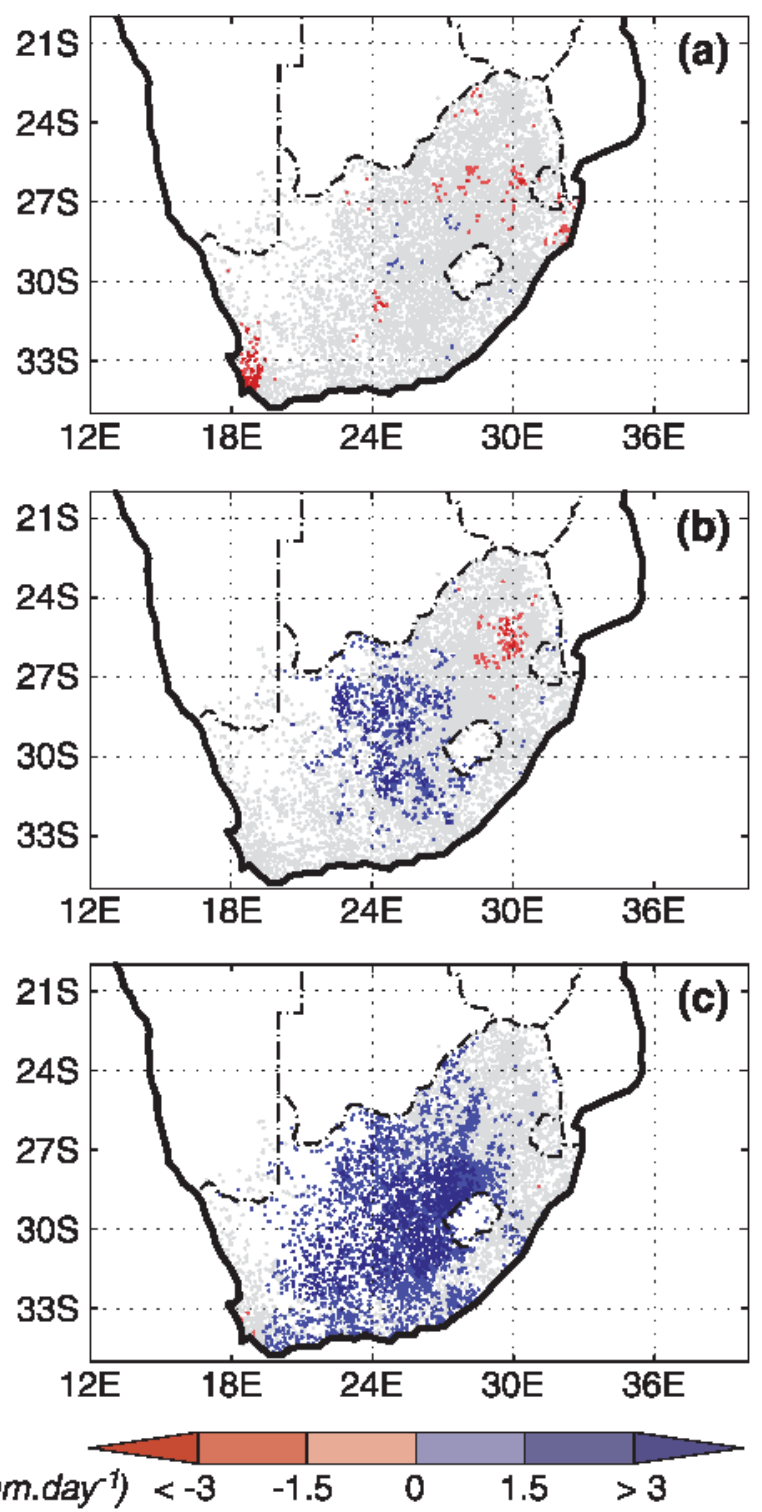

FIG. 11. (a) Composite analysis of the centered daily rainfall anomalies $\left(\mathrm{mm} \mathrm{day}^{-1}\right)$ between the positive and negative phases of the AAO during NDJF seasons of El Niño years. See text for definitions. The only rain gauge stations for which the difference is significant according to a two-tailed $t$ test at $95 \%$ are shown on the figure. See legend for color shading. (b) As in (a) but for neutral years. (c) As in (a) but for La Niña years.

northern part of the country is out of phase with the central parts where the signals are the strongest, confirming the pattern already shown in Fig. 9. Correlations over the Western Cape Province are, however, not significant and fail to complete the tripolar pattern. Lowerlayer mass convergence is favored over the west of SA, in relationship with a modification in the midlatitude westerly winds (Figs. 12d,e). Upper-layer divergence is also found over the whole subcontinent, resulting in 

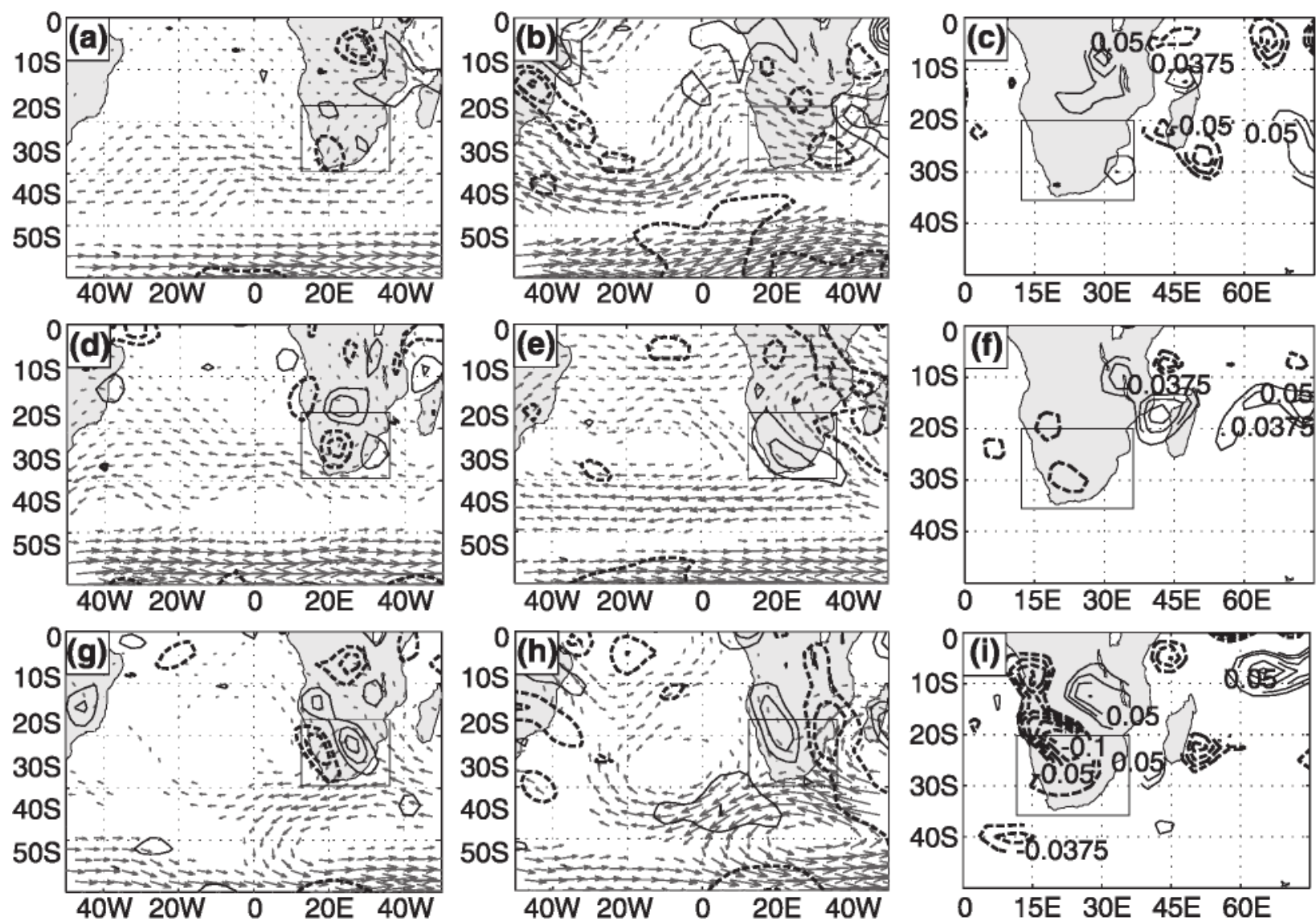

FIG. 12. (a) Composite analysis of the daily horizontal wind at $850 \mathrm{hPa}\left(\mathrm{m} \mathrm{s}^{-1}\right)$ between the positive and negative phases of the AAO during NDJF seasons of El Niño years. Only significant anomalies (Hotelling $t^{2}$ test, $95 \%$ level) are shown on the figure. Solid (dashed) contours denote areas where mass divergence is enhanced (weakened) by the positive phase of the AAO. Contour interval is $0.1 \mathrm{~s}^{-1}$ and the zero contour is omitted. The black box corresponds to the region, shown in Fig. 11, for which in situ rainfall records are available. (b) As in (a) but for the 200-hPa level. (c) As in (a) but for the vertical component of the wind at $500 \mathrm{hPa}\left(\mathrm{Pa} \mathrm{s}{ }^{-1}\right)$. Only significant anomalies ( $t$ test, 95\% level) are shown on the figure; contour interval is $0.0125 \mathrm{~Pa} \mathrm{~s}^{-1}$. Negative (positive) anomalies are contoured with dashed (solid) lines. (d)-(f) As in (a)-(c) but for neutral years. (g)-(i) As in (a)-(c) but for La Niña years.

weak ascending motion anomalies during the positive phase of the AAO (Fig. 12d). The latter is spatially limited and does not concern the eastern and northern part of the domain (where lower-layer divergence prevails). Close comparisons between the NCEP-2-derived atmospheric fields and in situ rainfall anomalies reveal a slight shift of the atmospheric structures toward the west, suggesting that the reanalyses may present regional biases over SA. The low amount of data used to guide the model and the rather low resolution of its grid are probably at the origin of these inconsistencies. In particular, one cannot expect the strong topographic influences in the eastern part of the country to be accurately simulated in NCEP-2 grids, which contribute to explain this apparent westward shift of the reanalyzed atmospheric configurations.

During La Niña years (Figs. 12g-i), the AAO influence on rainfall is strongest. Rainfall anomalies are significant over a large part of the domain (Fig. 11c). Wind anomalies are also spatially more developed in the lower, mid, and upper troposphere and of larger intensity (Figs. 12g-i). The southward shift of the westerlies is generally as pronounced as for other groups of years, but is associated with regional anticyclonic anomalies south of SA. Cyclonic anomalies prevail farther north in the subtropics, over the southern Atlantic and Indian basins. Strong ascents are found between these two cyclonic cells over central and western SA, extending toward the Congo Basin. They correspond to lower- (upper-) layer mass convergence (divergence) over western SA. On the contrary, over the eastern part of the domain subsiding motion is found, associated with lower- (upper-) layer divergence (convergence). These atmospheric patterns are once again slightly shifted toward the west compared to rainfall anomalies, reinforcing the statement that NCEP-2 reanalyses are perfectible over the region. 
Both La Niña conditions (at the interannual time scale) and the positive phase of the AAO (at the intraseasonal time scale), therefore, add their effects, which consist of a poleward shift in the westerlies and thus a weakening at the latitude of SA. A slower and less zonal subtropical jet is assumed to favor synoptic wave structures, such as identified over the southern Atlantic and Indian basins in Figs. 12g,h. For these reasons, these stationary wave patterns are hypothesized to concentrate mostly during the positive AAO events of La Niña years. Although its overall activity is rather coherent during the opposite phases of ENSO (Table 2), the AAO is thus more strongly involved in the SA intraseasonal variability during La Niña. Additional analyses are now required to confirm whether such wave structures are significantly more liable to occur when both La Niña and the positive phase of the AAO occur at the same time.

\section{Conclusions and discussion}

In this paper we first find that, in spite of its marked fluctuations in the 30-60-day range, the AAO does not clearly interact with the global-scale MJO activity. In the mid and high southern latitudes, the MJO rather shows a dipolar structure and its anomaly patterns do not present an annular nature. Recently, Kushner and Lee (2007) isolated regional-scale (wavenumber-3-4) eastward-propagating wave structures in the AAO patterns. Two main periodicities were identified, one of these being 40 days. We confirm here that the intraseasonal range indeed contains the most energetic AAO signals. However, we question to what extent the 40-day periodicities observed by the previous authors can relate to the regional MJO signature, instead of intrinsic modes of the AAO variability. Further studies are needed to resolve this issue.

At the interannual time scale, we confirm that the AAO is significantly related to ENSO during the austral summer season (November through February), that is, the period of the year during which the signals associated to El Niño or La Niña conditions reach their mature phase. Similar conclusions were already proposed in Fogt and Bromwich (2006) and L'Heureux and Thompson (2006). In addition to their findings, we show here that the statistical dependency between the AAO and ENSO is only found when seasonal mean fields, averaged over the four months of austral summer, are considered. Monthly fields fail to show significant results, which could be attributed to the weak month-to-month autocorrelation of the AAO. Given the loading pattern of the AAO index, which shows very strong (weak) correlation values over Antarctica (the southern midlatitudes), it is the changes in the vertical profile of the atmosphere over Antarctica rather than the changes over the circumpolar ocean that are important to explain seasonal fluctuations of the phase of the oscillation.

The linear relationship between the AAO and ENSO during austral summer questions to what extent two modes of climate variability that are linearly related interfere with each other from a statistical point of view, that is, without necessarily taking into consideration the physical processes involving their significant common variance. Predictions or diagnostics based on linear correlations with the AAO time series, but without removing the common variance with ENSO, are indeed likely to lead to biased results. Hence, the specific influence of each phenomenon must be isolated.

We chose one example, South Africa, to illustrate this issue. Our choice was motivated because the region experiences its heaviest rainfall during austral summer, and it is known to be under a strong influence of both MJO and ENSO. In addition, the importance of the AAO for interannual winter rainfall variability over the region was demonstrated by Reason and Rouault (2005a,b), so it is of interest to see if this relationship also holds for the summer season.

At the intraseasonal time scale, the opposite phases of the AAO have an impact on the daily rainfall amounts over southern Africa, the positive phase being associated with more abundant precipitation over the center of South Africa. This statistical relationship, significant on average, is, however, very weak during El Niño years but particularly strong during La Niña events and, to a lesser extent, neutral years. The very low common variance between the MJO and AAO demonstrates that these two modes of variability explain a complementary part of the rainfall variability. This result could be useful to improve the statistical models used to make seasonal forecasts over the region.

At the interannual time scale, the role of the AAO is more questionable. Linear correlations between the seasonal mean AAO index and the seasonal rainfall amounts over southern Africa depict a very significant linkage between these time series. However, this result is a statistical artifact and is likely due to the statistical dependence between AAO and ENSO during austral summer. After removing the influence of ENSO, the contribution of the AAO to modulating the rains becomes barely significant. Considering the linear dependency between these two modes of climate variability appears to be fundamental in order to avoid biased predictions or diagnostics.

Additional work is now needed to quantify that part of the variance of the rain that is related to the AAO variability. The reason why the AAO has a stronger influence on South Africa during La Niña years remains 
also to be investigated. We suggested here that the positive phase of the AAO and La Niña combine their effects to shift the midlatitude westerlies toward the south and reduce their speed at the subtropical latitudes. Hence the southern subtropical jet could be reduced when both modes add their influence, resulting in enhanced probabilities of rain-causing synoptic waves. From the results and the questions raised in section 3a, more detailed studies investigating the characteristics of the variability in the regional and global signatures of the AAO at the subseasonal time scales are also needed. These topics will be investigated in future work.

Acknowledgments. The EMD code has been made available by Patrick Flandrin online at http://perso. ens-lyon.fr/patrick.flandrin/emd.html. The MEI, OLR, and NCEP-2 fields were obtained from the Climate Diagnostics Center (information online at http://www. cdc.noaa.gov). The HadISST data were provided by the Met Office (information online at http://www.badc.nerc. ac.uk/data/hadisst/). The Wheeler and Hendon MJO indices were provided through the Australian Bureau of Meteorology (information online at http://www.bom. gov.au).

This work was carried out at the University of Cape Town as part of the PICS PESOCA exchange program cofunded by France and South Africa. Benjamin Pohl thanks the Department of Oceanography at UCT for its hospitality. Nicolas Fauchereau and Mathieu Rouault thank funding from WRC project K5/1747. The authors thank Matt Wheeler as well as three anonymous reviewers for helpful comments on the manuscript.

\section{REFERENCES}

Arblaster, J. M., and G. A. Meehl, 2006: Contributions of external forcings to southern annular mode trends. J. Climate, 19, 28962905.

Beltrando, G., and D. L. Cadet, 1990: Interannual variability of the short rain season in East Africa: Relationships with general atmospheric circulation. Veille Climatique Satell., 33, 19-36.

Black, E., J. Slingo, and K. R. Sperber, 2003: An observational study of the relationship between excessively strong short rains in coastal East Africa and Indian Ocean SST. Mon. Wea. Rev., 131, 74-94.

Carvalho, L. M. V., C. Jones, and T. Ambrizzi, 2005: Opposite phases of the Antarctic Oscillation and relationships with intraseasonal to interannual activity in the tropics during the austral summer. J. Climate, 18, 702-718.

Ciasto, L. M., and D. W. J. Thompson, 2008: Observations of largescale ocean-atmosphere interaction in the Southern Hemisphere. J. Climate, 21, 1244-1259.

Codron, F., 2005: Relation between annular modes and the mean state: Southern Hemisphere summer. J. Climate, 18, 320-330.

Donald, A., H. Meinke, B. Power, A. de H. N. Maia, M. C. Wheeler, N. White, R. C. Stone, and J. Ribbe, 2006: Near-global impact of the Madden-Julian Oscillation on rainfall. Geophys. Res. Lett., 33, L09704, doi:10.1029/2005GL025155.

Dyer, T. G. J., 1979: Rainfall along the east coast of southern Africa, the Southern Oscillation and the latitude of the subtropical high pressure belt. Quart. J. Roy. Meteor. Soc., 105, 445-451.

Fauchereau, N., B. Pohl, C. J. C. Reason, M. Rouault, and Y. Richard, 2009: Recurrent daily OLR patterns in the southern Africa/southwest Indian Ocean region, implications for South African rainfall and teleconnections. Climate Dyn., 32, 575-591.

Feldstein, S., and S. Lee, 1998: Is the atmospheric zonal index driven by an eddy feedback? J. Atmos. Sci., 55, 3077-3086.

Fogt, R. L., and D. H. Bromwich, 2006: Decadal variability of the ENSO teleconnection to the high-latitude South Pacific governed by coupling with the southern annular mode. J. Climate, 19, 979-997.

Gong, D., and S. Wang, 1999: Definition of Antarctic Oscillation index. Geophys. Res. Lett., 26, 459-462.

Hastenrath, S., 2000: Zonal circulations over the equatorial Indian Ocean. J. Climate, 13, 2746-2756.

Hendon, H. H., D. W. Thompson, and M. C. Wheeler, 2007: Australian rainfall and surface temperature variations associated with the Southern Hemisphere annular mode. J. Climate, 20, 2452-2467.

Huang, N. E., and Z. Wu, 2008: A review on Hilbert-Huang transform: Method and its applications to geophysical studies. Rev. Geophys., 46, RG2006, doi:10.1029/2007RG000228.

- Z. Shen, S. R. Long, M. C. Wu, and H. H. Shih, 1998: The empirical mode decomposition and Hilbert spectrum for nonlinear and non-stationary time series analysis. Proc. Roy. Soc. London, 454, 903-995.

Jones, J. M., and M. Widmann, 2003: Instrument and tree-ringbased estimates of the Antarctic Oscillation. J. Climate, 16, 3511-3524.

- , and - 2004: Early peak in Antarctic Oscillation index. Nature, 432, 290-291, doi:10.1038/432290b.

Kalnay, E., and Coauthors, 1996: The NCEP/NCAR 40-Year Reanalyses Project. Bull. Amer. Meteor. Soc., 77, 437-471.

Kanamitsu, M., W. Ebisuzaki, J. Woollen, S.-K. Yang, J. J. Hnilo, M. Fiorino, and G. L. Potter, 2002: NCEP-DOE AMIP II Reanalysis (R-2). Bull. Amer. Meteor. Soc., 83, 1631-1643.

Kushner, P. J., and G. Lee, 2007: Resolving the regional signature of the annular modes. J. Climate, 20, 2840-2852.

L'Heureux, M. L., and W. J. Thompson, 2006: Observed relationships between the El Niño-Southern Oscillation and the extratropical zonal-mean circulation. J. Climate, 19, 276-287.

Lindesay, J. A., 1988: South African rainfall, the Southern Oscillation and a Southern Hemisphere semi-annual cycle. Int. J. Climatol., 8, 17-30.

Lorenz, D. J., and D. L. Hartmann, 2001: Eddy-zonal flow feedback in the Southern Hemisphere. J. Atmos. Sci., 58, 33123327.

Lynch, S. D., 2003: Development of a RASTER database of annual, monthly and daily rainfall for Southern Africa. Water Research Commission Rep. 1156/1/03, 78 pp.

Madden, R. A., and P. R. Julian, 1994: Observations of the 40-50 day tropical oscillation-A review. Mon. Wea. Rev., 122, 814-837.

Matthews, A. J., and M. P. Meredith, 2004: Variability of Antarctic circumpolar transport and the Southern Annular Mode associated with the Madden-Julian Oscillation. Geophys. Res. Lett., 31, L24312, doi:10.1029/2004GL021666.

Meneghini, B., I. Simmonds, and I. N. Smith, 2007: Association between seasonal Australian rainfall and the southern annular mode. Int. J. Climatol., 27, 109-121. 
Pohl, B., Y. Richard, and N. Fauchereau, 2007: Influence of the Madden-Julian oscillation on southern African summer rainfall. J. Climate, 20, 4227-4242.

Rayner, N. A., D. E. Parker, E. B. Horton, C. K. Folland, L. V. Alexander, D. P. Rowell, E. C. Kent, and A. Kaplan, 2003: Global analyses of sea surface temperature, sea ice, and night marine air temperature since the late nineteenth century. J. Geophys. Res., 108, 4407, doi:10.1029/2002JD002670.

Reason, C. J. C., and M. Rouault, 2005a: Links between the Antarctic Oscillation and winter rainfall over western South Africa. Geophys. Res. Lett., 32, L07705, doi:10.1029/2005GL022419.

— , and — 2005b: The southern annular mode and South African rainfall. CLIVAR Exchanges, No. 10, International CLIVAR Project Office, Southampton, United Kingdom, 10-11.

- R. J. Allan, J. A. Lindesay, and T. J. Ansell, 2000: ENSO and climatic signals across the Indian Ocean basin in the global context: Part I. Interannual composite patterns. Int. J. Climatol., 20, 1285-1327.

Richard, Y., S. Trzaska, P. Roucou, and M. Rouault, 2000: Modification of the southern African rainfall variability/El NiñoSouthern Oscillation relationship. Climate Dyn., 16, 883-895.

-, N. Fauchereau, I. Poccard, M. Rouault, and S. Trzaska, 2001: 20th century droughts in southern Africa: Spatial and tem- poral variability, teleconnections with oceanic and atmospheric conditions. Int. J. Climatol., 21, 873-885.

Rogers, J. C., and H. van Loon, 1982: Spatial variability of sea level pressure and 500-mb height anomalies over the Southern Hemisphere. Mon. Wea. Rev., 110, 1375-1392.

Seager, R., N. Harnik, Y. Kushnir, W. Robinson, and J. Miller, 2003: Mechanisms for hemispherically symmetric climate variability. J. Climate, 16, 2960-2978.

Thompson, D. W., and J. M. Wallace, 2000: Annular modes in the extratropical circulation. Part I: Month-to-month variability. J. Climate, 13, 1000-1016.

— , and S. Solomon, 2002: Interpretation of recent Southern Hemisphere climate change. Science, 296, 895-899.

Wheeler, M. C., and H. H. Hendon, 2004: An all-season realtime multivariate MJO index: Development of an index for monitoring and prediction. Mon. Wea. Rev., 132, 19171932.

Wolter, K., and M. S. Timlin, 1993: Monitoring ENSO in COADS with a seasonally adjusted principal component index. Proc. 17th Climate Diagnostics Workshop, Norman, OK, NOAA/ NMC/CAC and Cosponsors, 52-57.

Zhang, C., 2005: Madden-Julian Oscillation. Rev. Geophys., 43, RG2003, doi:10.1029/2004RG000158. 